\title{
Small-angle Compton Scattering to Determine the Depth of a Radioactive Source in Matter
}

\author{
R.B. Oberer \\ C.A. Gunn \\ L.G. Chiang \\ R.E. Valiga \\ J.A. Cantrell
}

April 2011

\author{
Prepared by \\ Babcock \& Wilcox Technical Services Y-12, LLC \\ Management \& Operating Contractor \\ for the \\ Y-12 National Security Complex \\ under Contract No. DE-AC05-00OR22800 \\ with the \\ U.S. Department of Energy \\ National Nuclear Security Administration
}




\section{Disclaimer}

This report was prepared as an account of work sponsored by an agency of the United States Government. Neither the United States Government nor any agency thereof, nor any of their employees, makes any warranty, express or implied, or assumes any legal liability or responsibility for the accuracy, completeness, or usefulness of any information, apparatus, product, or process disclosed, or represents that its use would not infringe privately owned rights. Reference herein to any specific commercial product, process, or service by trade name, trademark, manufacturer, or otherwise, does not necessarily constitute or imply its endorsement, recommendation, or favoring by the United States Government or any agency thereof. The views and opinions of authors expressed herein do not necessarily state or reflect those of the United States Government or any agency thereof. 


\section{Introduction}

A gamma-ray peak in a spectrum is often accompanied by a discontinuity in the Compton continuum at the peak. The Compton continuum results from Compton scattering in the detector. The discontinuity at a peak results from small-angle Compton scattering by the gamma rays in matter situated directly between the gamma-ray source and the detector. The magnitude of this discontinuity with respect to the gamma-ray peak is therefore an indicator of the amount of material or shielding between the gamma-ray source and the detector.

This small-angle scattering was used to determine the depth of highly-enriched uranium (HEU) solution standards in a concrete floor mockup. The empirical results of the use of this smallangle scattering discontinuity in a concrete floor experiment will be described. A Monte Carlo calculation of the experiment will also be described. In addition, the depth determined from small-angle scattering was used in conjunction with differential attenuation to more accurately measure the uranium content of the mockup.

Following these empirical results, the theory of small-angle scattering will be discussed. The magnitude of the discontinuity compared to the peak count rate is directly related to the depth of the gamma-ray source in matter. This relation can be described by relatively simple mathematical expressions.

This is the first instance that we are aware of in which the small-angle Compton scattering has been used to determine the depth of a radioactive source. Furthermore this is the first development of the theoretical expressions for the magnitude of the small-angle scattering discontinuity.

\section{Floor measurement issue}

Over the years, numerous NDA holdup measurements have been made on the HEU holdup in the floors of chemical processing areas. These measurements result in large quantities of suspected HEU with large uncertainties. Most of the uncertainty is attributed to the uncertainty in the amount of attenuation of the $185.71 \mathrm{keV}$ gamma ray. Of the many factors that affect this attenuation, the unknown depth distribution of the uranium in the floor is the primary contributor to this uncertainty. Differential attenuation of the U-235 and Tl-208 gamma rays has been proposed to determine the depth distribution. ${ }^{1}$ In addition to differential attenuation, the smallangle scattering discontinuity may also indicate the depth of the uranium contamination.

\footnotetext{
${ }^{1}$ R. B. Oberer, L. G. Chiang, C. A. Gunn, "The Use of High Resolution Gamma Spectroscopy to Improve FloorHoldup Measurements," Y/EN-8269, May 26, 2009.
} 


\section{Small-angle scattering}

In a gamma-ray spectrum, one can frequently observe a discontinuity in the Compton background at a gamma-ray peak. Figure 1 shows this discontinuity at the $185.71 \mathrm{kev}$ gammaray peak. The Compton continuum is caused by Compton scattering in the detector from higher energy gamma rays. The discontinuity at a gamma-ray peak, on the other hand, is caused by small-angle Compton scattering in material directly between the gamma-ray source and the detector. These small-angle scatters reduce the gamma-ray energy by a small amount from the peak energy.

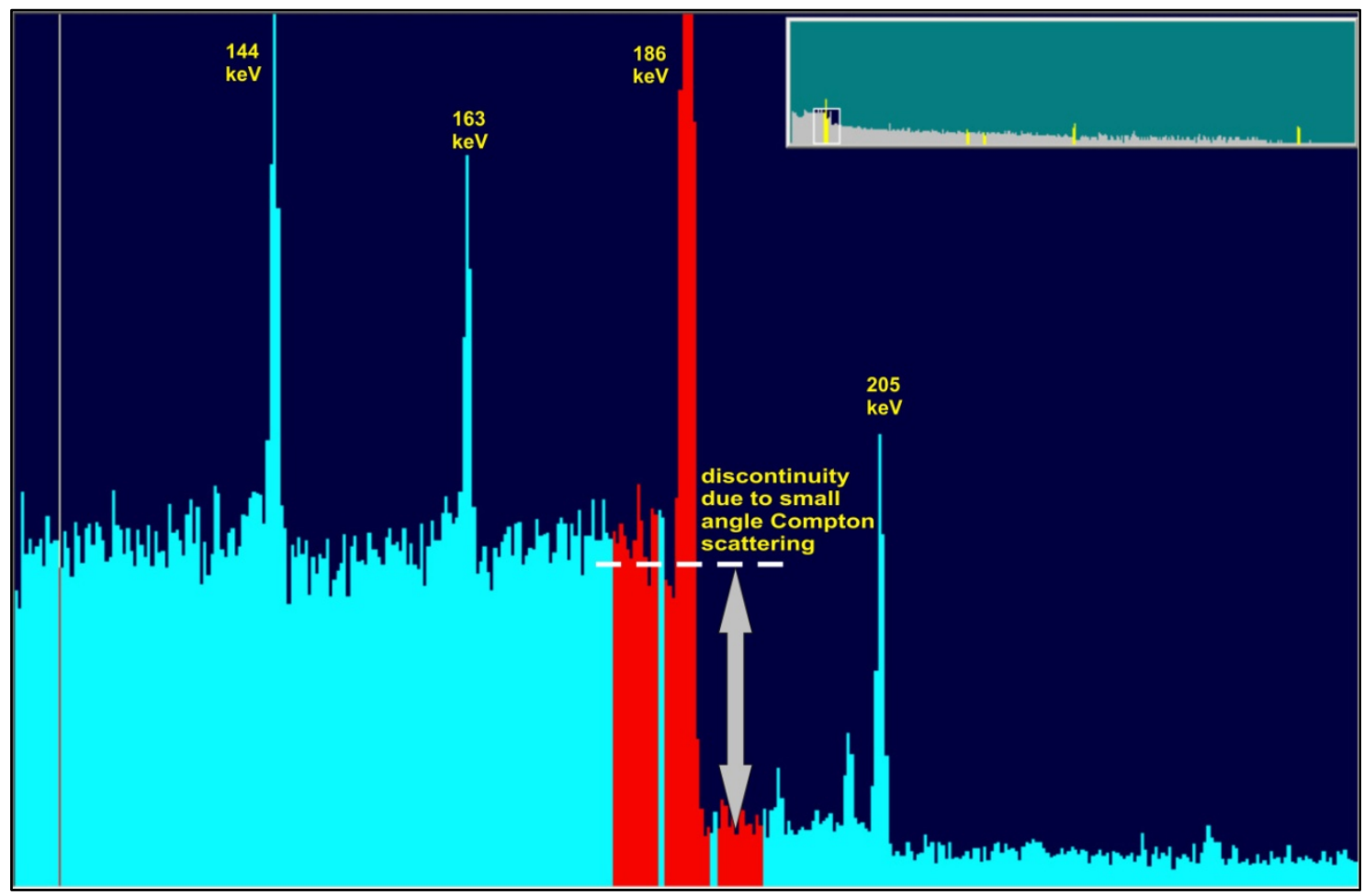

Figure 1: Spectrum at the 186kev gamma-ray peak showing the typical discontinuity. This discontinuity is caused by small-angle Compton scattering in material between the source and detector. The magnitude of the discontinuity is defined as the count rate in the ROI before the peak minus the ROI after the peak, divided by the energy width of the ROI, $4.62 \mathrm{keV}$ in this case.

A gamma ray loses part of its energy from Compton scattering. The ratio of this new energy $\mathrm{E}$ to the original gamma-ray energy $\mathrm{E}_{\gamma}$ is given by

$$
\left(\frac{E}{E_{\gamma}}\right)=\frac{1}{1+\frac{E_{\gamma}}{m_{e} c^{2}}(1-\cos (\theta))}
$$

When the scattering angle $\theta$ approaches zero, the scattered gamma ray has the same or nearly the same energy as the original gamma ray. It is this small-angle Compton scattering that produces 
the discontinuity at a gamma-ray peak. Because the scattered gamma ray continues on in nearly the same direction as the original, it can only be caused by material directly between the source and detector.

\section{Empirical results}

\section{Tile experiment}

An experiment was performed with HEU planar standards and seventeen concrete tiles. The setup is shown in Figure 2. Fifteen of the tiles were quarter inch thick Hardie board, cut into 11 $7 / 8$ inch square tiles. The tiles weighed about $785 \mathrm{~g} \pm 7 \mathrm{~g}$. The density was therefore $1.36 \mathrm{~g} / \mathrm{cm}^{3}$. Two of the tiles were patio blocks. The patio blocks were also $117 / 8$ inch square but were $15 / 8$ inches thick and weighed about ten times as much. The density of the patio blocks was $2.07 \mathrm{~g} / \mathrm{cm}^{3}$. The HEU standards were placed between various tiles as shown.

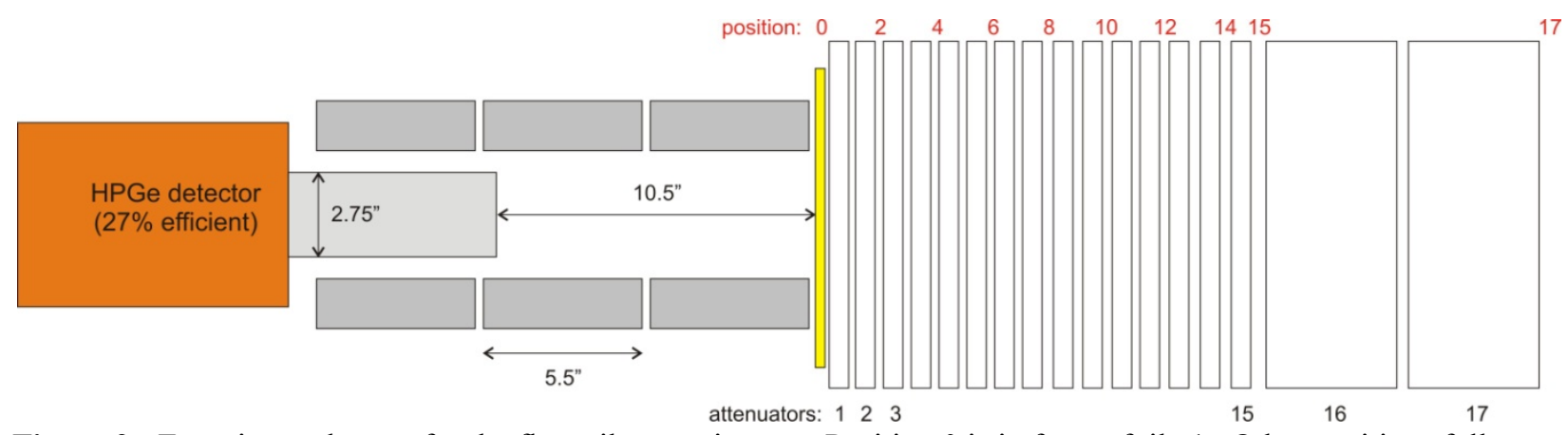

Figure 2: Experimental setup for the floor tile experiments. Position 0 is in front of tile 1. Other positions follow the tile number.

The six planar standards used in this experiment were manufactured by Y-12 Development Division. $^{2}$ The source material was $96.312 \%$ enriched uranyl nitrate hexahydrate (UNH). The mass fraction of uranium is $0.4971 \mathrm{gU} / \mathrm{gUNH}$.

The specifications of the uranium standards are summarized in Table 1 below. The masses of UNH and U-235 for each standard are shown in the last two columns. The values for the declared amounts of U-235 are computed by multiplying the mass of UNH by the product of $0.4971 \mathrm{gU} / \mathrm{gUNH}$ and $0.96312 \mathrm{gU} 235 / \mathrm{gU}$.

\footnotetext{
${ }^{2}$ Y-12 Working Reference Material Certificate of Analysis Uranium Non-Destructive Analysis Line and Planar Sources, Jon Neuhoff, Director New Brunswick Laboratory, Argonne, Illinois, August 30, 2009
} 
Table 1: Uranium Standards manufactured by Y-12 Development ${ }^{3}$

\begin{tabular}{|c|c|c|c|c|c|}
\hline ID & $\begin{array}{l}\text { Drawing } \\
\text { Number }\end{array}$ & $\begin{array}{c}\text { Nominal } \\
\text { Dimensions }\end{array}$ & $\begin{array}{l}\mathrm{UNH} \\
\text { mass } \\
(\mathrm{g}) \\
\end{array}$ & $\begin{array}{c}\text { U-235 mass } \\
(\mathrm{g})\end{array}$ & $\begin{array}{c}\text { U-235 areal } \\
\text { density } \\
\left(\mathrm{g} / \mathrm{cm}^{2}\right) \\
\end{array}$ \\
\hline P-96-001 & 4P7-10-08-PS1 & $10 " \times 10 "$ & 44.80 & $21.45 \pm 0.52$ & 0.0333 \\
\hline F-96-001 & \multirow{5}{*}{ 4P7-10-08-FS1 } & \multirow{5}{*}{$9 " \times 18 "$} & 4.60 & $2.2 \pm 0.19$ & 0.0022 \\
\hline F-96-002 & & & 14.30 & $6.85 \pm 0.24$ & 0.0065 \\
\hline F-96-003 & & & 14.30 & $6.85 \pm 0.24$ & 0.0065 \\
\hline F-96-004 & & & 34.72 & $16.62 \pm 0.42$ & 0.0160 \\
\hline F-96-005 & & & 46.30 & $22.17 \pm 0.53$ & 0.0212 \\
\hline
\end{tabular}

The planar sources were constructed of UNH deposited on 3 plies of Hazmat Pads sandwiched between two 1/16" sheets of polyethylene terephthalate glycol. The 3 plies of Hazmat material are 0.047 " thick.

To calibrate the effect of small-angle scattering, Standard P-96-001 was placed at various positions between the concrete tiles and spectra were collected using a heavily collimated HPGe detector. The positions measured were Position $0,1,2,4,6,8,10,12,14,16$, and 17. At Position 0 , the standard is placed before the tiles without any concrete attenuation. In Position 1 the standard was placed after the first $1 / 4$ inch thick tile and so forth.

The magnitude of the discontinuity was then calculated by taking the difference between the count rate in the ROI before the $185.71 \mathrm{keV}$ peak and the ROI after the peak as shown in Figure 1. This difference was divided by the net count rate in the $185.71 \mathrm{keV}$ peak. The width of the $\mathrm{ROI}$ in this case was $4.62 \mathrm{keV}$. These results are shown in Figure 3.

\footnotetext{
${ }^{3}$ Uncertainty Evaluation for Y-12 Line, Filter and Planar NDA Standards, P. Mason, New Brunswick Laboratory, NBL-RM-2009-Y12 NDA WRM
} 


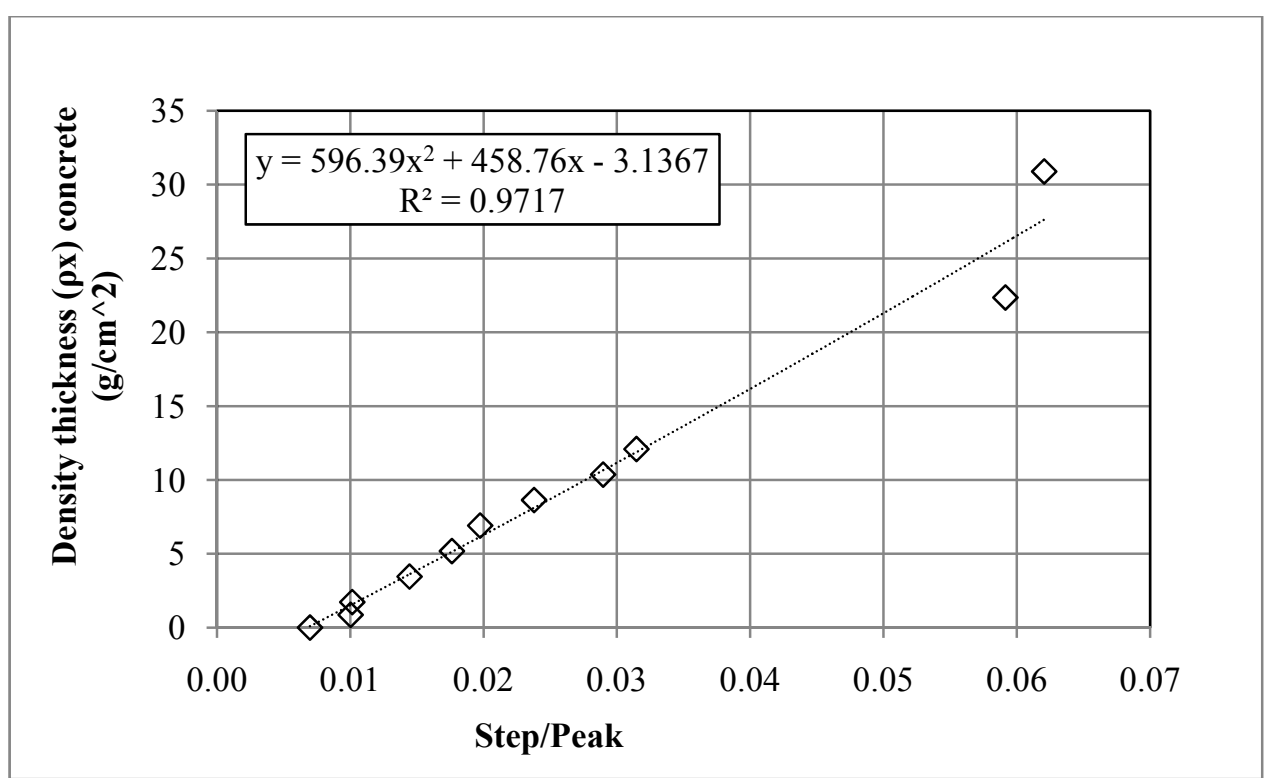

Figure 3: Magnitude of the discontinuity at the $185.71 \mathrm{keV}$ gamma-ray peak in cps for various positions in the floor tile experiment divided by the net peak height for Standard P-96-001 at various discrete positions. The peak of 0.007 at Position 0 apparently comes from small-angle scattering in the detector enclosure.

To represent a continuous, uniform distribution of uranium to some depth $x$, the data in Figure 3 was numerically integrated. The resulting calibration is shown in Figure 4.

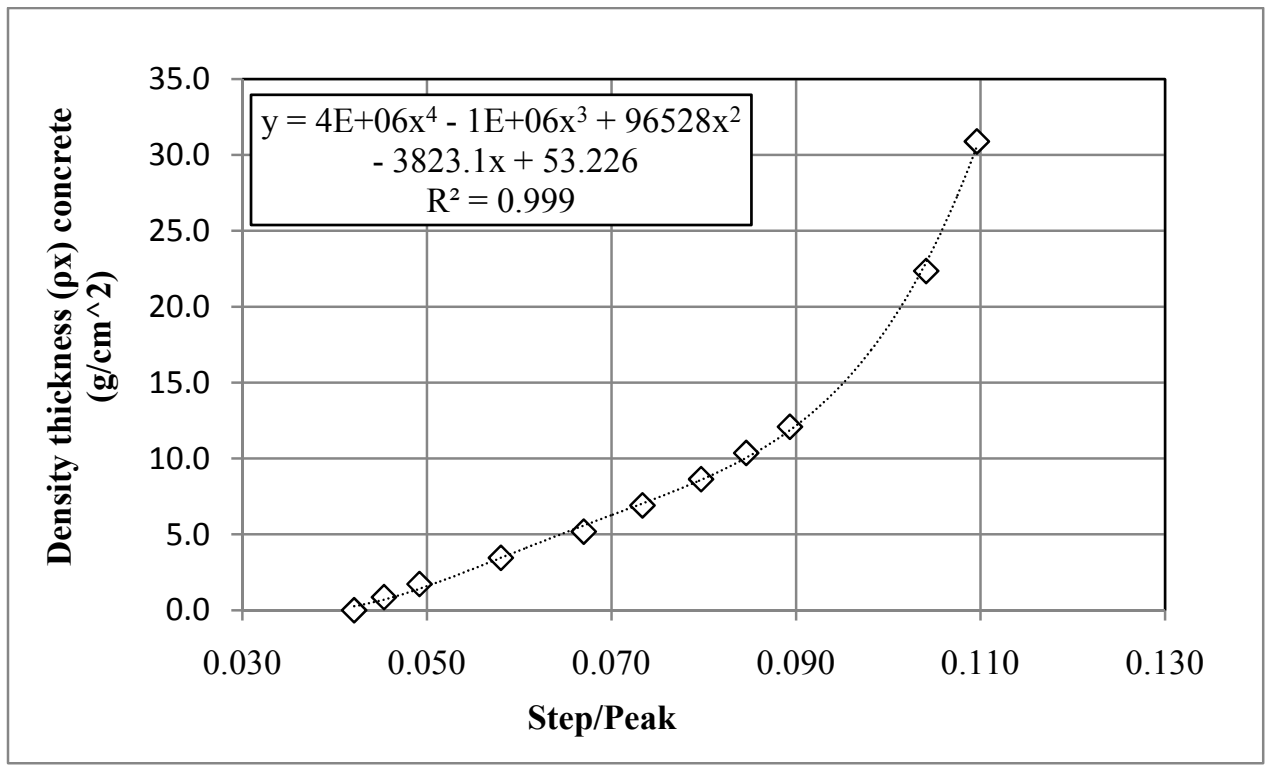

Figure 4: Magnitude of the discontinuity divided by peak data from Figure 3, numerically integrated to represent a continuous, uniform distribution of source HEU in the concrete. A calibration curve was also fit to this data.

Next, a set of nine test configurations was arranged as shown in Table 2. In the first configuration, all six planar standards were placed at position zero. In the second configuration, six standards (P-96-001, F-96-005, F-96-004, F-96-003, F-96-002, F-96-001) were placed in Positions 0 through 5. These six standards were placed at various positions in configurations 1 , 
2,3 , and 9. In configurations 4, 5, 6, 7, and 9, P-96-001 was eliminated and the remaining five standards were used. The total areal density of U-235 was therefore either $0.086 \mathrm{~g} / \mathrm{cm}^{2}$ or $0.052 \mathrm{~g} / \mathrm{cm}^{2}$.

Table 2: Nine cases were run with multiple standards inserted into the concrete at various depths from the setup shown in Figure 2. The first row is the position number. The second row is the density thickness of concrete $\left(\mathrm{g} / \mathrm{cm}^{2}\right)$ between the standard and detector at that position. The data is the areal density of U-235 $\left(\mathrm{g} / \mathrm{cm}^{2}\right)$ at that depth.

\begin{tabular}{|c|c|c|c|c|c|c|c|c|c|c|}
\hline $\begin{array}{c}\text { Position } \\
\text { Number }\end{array}$ & 0 & 1 & 2 & 3 & 4 & 5 & 6 & 8 & 10 & 15 \\
\hline $\begin{array}{c}\text { Density } \\
\text { Thickness } \\
\left(\mathrm{g} / \mathrm{cm}^{2}\right)\end{array}$ & 0.00 & 0.86 & 1.73 & 2.59 & 3.45 & 4.32 & 5.18 & 6.91 & 8.64 & 12.95 \\
\hline Case 1 & 0.0856 & & & & & & & & & \\
\hline Case 2 & 0.0332 & 0.0212 & 0.0160 & 0.0065 & 0.0065 & 0.0022 & & & & \\
\hline Case 3 & 0.0332 & & 0.0212 & & 0.0160 & & 0.0065 & 0.0065 & 0.0022 & \\
\hline Case 4 & 0.0212 & 0.0225 & 0.0065 & 0.0022 & & & & & & \\
\hline Case 5 & 0.0212 & 0.0160 & 0.0065 & 0.0065 & 0.0022 & & & & & \\
\hline Case 6 & 0.0212 & 0.0160 & & 0.0065 & & & 0.0065 & & 0.0022 & \\
\hline Case 7 & 0.0212 & & 0.0160 & & 0.0065 & & 0.0065 & 0.0022 & & \\
\hline Case 8 & 0.0212 & & 0.0160 & & 0.0065 & & 0.0065 & 0.0022 & & 0.0332 \\
\hline Case 9 & 0.0022 & & 0.0065 & & 0.0065 & & 0.0160 & 0.0212 & & \\
\hline
\end{tabular}

\section{Differential attenuation analysis}

Originally the depth distribution was going to be determined by differential attenuation on the U235 gamma rays and Tl-208 gamma rays from U-232. However, the count rates from the Tl-208 gamma rays from the standards were not great enough to produce reliable results. Furthermore, only the $185.71 \mathrm{keV}$ and $143.76 \mathrm{keV}$ gamma ray from U-235 were useful in the acquired spectra. Two parameters are typically adjusted for a differential attenuation analysis: the densitythickness of the contaminated matrix $\rho x$ and the mass-attenuation coefficient $\mu$ with the uranium fraction. The T1-208 gamma rays are more sensitive to matrix density thickness and are therefore used to determine the density-thickness adjustment. However, because these gamma rays were not abundant enough, another indicator was needed. The small-angle scattering discontinuity was used in its place.

The equation in Figure 4 was used as a calibration to determine the depth of the uranium distribution in the nine distributed cases. This calibration can also be determined theoretically from Equation (7). The development of the theory is described below. The results from various analysis approaches are shown in Table 3 and Figure 5. 
Table 3: Results of several methods to measure the areal density of U-235 in the experimental setup from Table 2 and Figure 2.

\begin{tabular}{|r|r|r|r|r|}
\hline & $\begin{array}{c}\text { Spreadsheet } \\
\text { Actual } \\
\text { depth }\end{array}$ & $\begin{array}{c}\text { Spreadsheet } \\
\text { Assumed } \\
\text { 4" depth }\end{array}$ & $\begin{array}{c}\text { ISOTOPIC } \\
\text { Assumed } \\
\text { 4" depth }\end{array}$ & $\begin{array}{c}\text { Small } \\
\text { Angle }\end{array}$ \\
\hline Actual Areal Density =0.085 gU235/cm ${ }^{2}$ \\
\hline Case 1 & 0.072 & 0.096 & 0.129 & 0.079 \\
\hline Case 2 & 0.084 & 0.103 & 0.121 & 0.089 \\
\hline Case 3 & 0.083 & 0.086 & 0.107 & 0.087 \\
\hline Case 8 & 0.085 & 0.085 & 0.077 & 0.082 \\
\hline Average: & 0.081 & 0.092 & 0.108 & 0.084 \\
\hline $\begin{array}{r}\text { Standard } \\
\text { deviation: }\end{array}$ & 0.006 & 0.009 & 0.023 & 0.004 \\
\hline Actual Areal Density $=0.052 \mathrm{gU} 235 / \mathrm{cm}^{2}$ & & \\
\hline Case 4 & 0.052 & 0.070 & 0.070 & 0.051 \\
\hline Case 5 & 0.045 & 0.052 & 0.069 & 0.050 \\
\hline Case 6 & 0.048 & 0.052 & 0.065 & 0.052 \\
\hline Case 7 & 0.051 & 0.054 & 0.065 & 0.046 \\
\hline Case 9 & 0.040 & 0.045 & 0.041 & 0.054 \\
\hline Average: & 0.047 & 0.055 & 0.062 & 0.050 \\
\hline $\begin{array}{r}\text { Standard } \\
\text { deviation: }\end{array}$ & 0.005 & 0.009 & 0.012 & 0.003 \\
\hline
\end{tabular}

The second column in Table 3 shows the differential attenuation results, making use of the known location of the uranium standards. In that method, the starting density-thickness of the floor comes from the Position column in Table 2. For example Case 2 would be $4.32 \mathrm{~g} / \mathrm{cm}^{2}$. The fraction of uranium used to calculate the mass-attenuation coefficient $\mu$ is then adjusted to agree with the measurement result. The density-thickness of the concrete is then adjusted to equalize the activities for both the $144 \mathrm{keV}$ and $186 \mathrm{keV}$ gamma rays.

In Column 3 of Table 3, the initial thickness of concrete is set to be four inches with a density of $1.36 \mathrm{~g} / \mathrm{cm}^{3}$. Making a guess of the thickness, in this case four inches, is far more realistic since the deposit depth is unknown for an actual floor measurement. The iterative process then proceeds as before. These results are shown in Figure 5 as the green triangles.

In Column 3, the approach is similar to the previous with the thickness of concrete set to four inches. However, rather than A spreadsheet, ISOTOPIC ${ }^{4}$ is used to adjust the density of the concrete and fraction of uranium. In this method, no iteration is attempted to make the uranium fraction agree with the measured result. In the absence of the information from the Tl-208 gamma rays, the matrix density thickness and uranium fraction are adjusted to minimize the differences in activity for the $144 \mathrm{keV}$ and $186 \mathrm{keV}$ gamma rays. These results are shown in Figure 5 as blue diamonds.

\footnotetext{
${ }^{4}$ ORTEC ISOTOPIC Supervisor and Operator, Program for Radioactive Waste Characterization, ISOPLUS-B32 Software User's Manual (2 Volumes).
} 
Finally, in Column 5 of Table 3, the initial density-thickness of concrete is determined from the small-angle scattering discontinuity from the calibration in Figure 4. The fraction of uranium is then adjusted so that the results for both the $144 \mathrm{keV}$ and $186 \mathrm{keV}$ gamma rays agree. This method produced the most accurate and precise results of the four methods. The results are shown in Figure 5 as red squares.

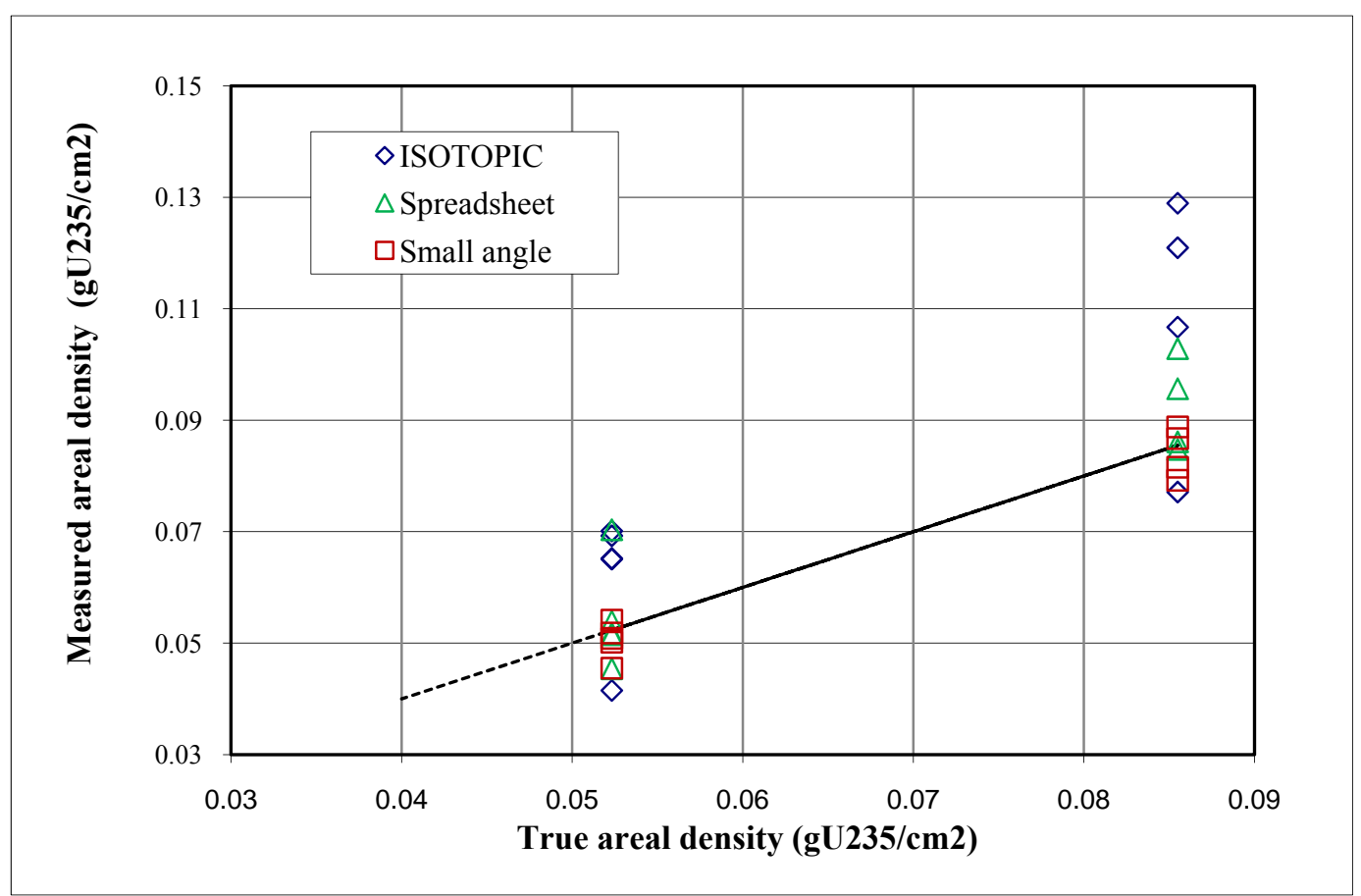

Figure 5: Results of NDA measured areal density of U-235. "ISOTOPIC" is from Column 4 of Table 3. "Spreadsheet" is from Column 3 of Table 3. "Small angle" is from Column 5 of Table 3.

\section{Monte Carlo calculation}

A Monte Carlo calculation was also performed to study the small-angle scattering discontinuity using MCNP. ${ }^{5}$ The geometry is shown in Figure 6 . The density of the concrete was $2.3 \mathrm{~g} / \mathrm{cm}^{3}$. The composition of the concrete is shown in Table 5. The results of these calculations are shown in Figures 11, 12, 13, and 15 in the theoretical section of this paper.

\footnotetext{
${ }^{5}$ X-5 Monte Carlo Team, ed., "MCNP - A General Monte Carlo N-Particle Transport Code-Version 5," Los Alamos National Laboratory report LA-UR-03-1987 (April 2003, Rev. February 2008).
} 


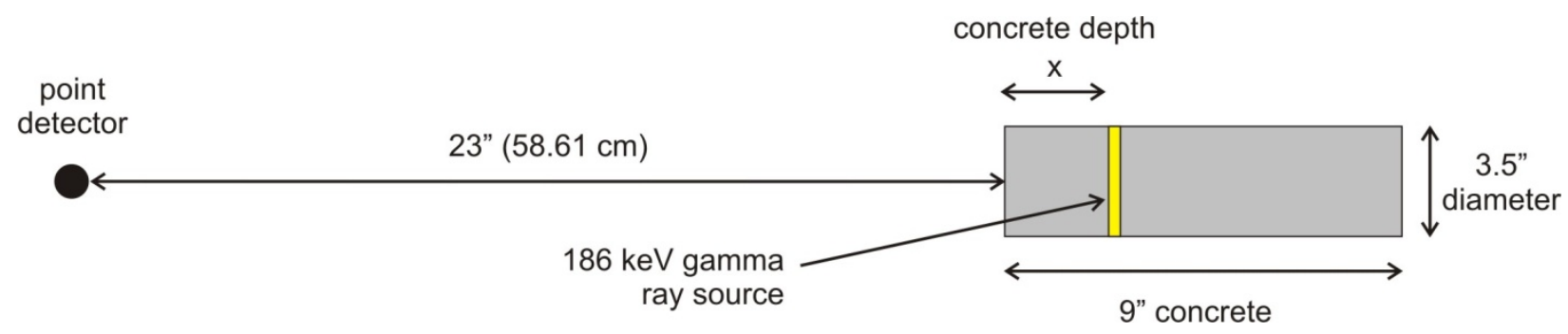

Figure 6: Geometry for the small-angle scattering from concrete for a U-235 planar source at a discrete depth, $\boldsymbol{x}$.

A sample spectrum from the Monte Carlo calculation is shown in Figure 7. The detections by a point detector from a planar source at a depth of $10.26 \mathrm{~cm}$ were tallied in $2.5 \mathrm{keV}$ energy bins to produce the spectrum. This source included the $144 \mathrm{keV}, 163 \mathrm{keV}, 186 \mathrm{keV}$, and $205 \mathrm{keV}$ gamma rays form $U-235$. However, unlike $U-235$, the emission probabilities for these gamma rays were equal. The discontinuity from small-angle Compton scattering is clearly visible.

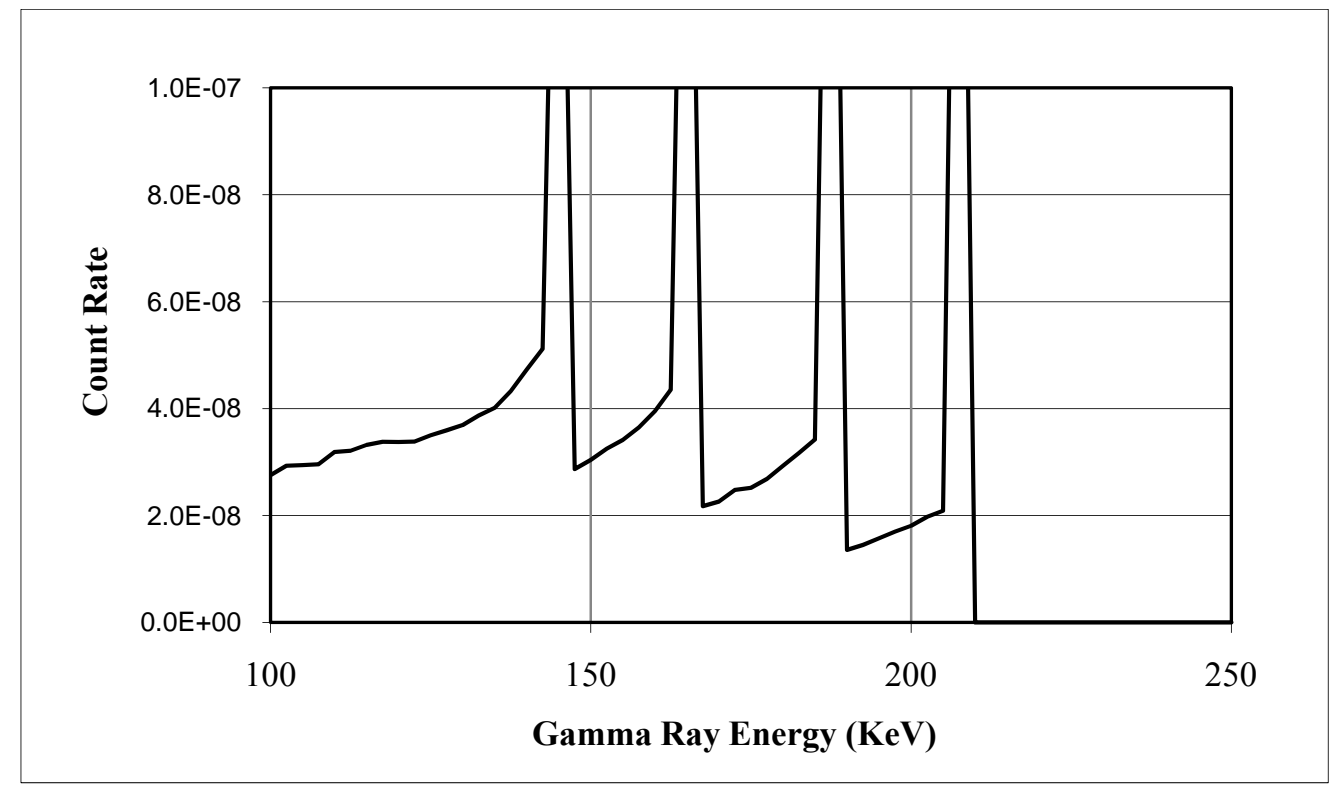

Figure 7: Spectrum from the Monte Carlo calculations comparable to Figure 1 showing the discontinuity from smallangle Compton scattering. Unlike the actual emission rates from $\mathrm{U}-235$, the $144 \mathrm{keV}, 163 \mathrm{keV}, 186 \mathrm{keV}$ and $205 \mathrm{keV}$ gamma rays were all emitted with equal probabilities. The detection rate is for the emission of one gamma ray. It therefore represents the probability of detection.

\section{Small-angle-scattering theory}

As gamma rays travel through material they interact through photoelectric effect, Compton scattering, and pair production. The number of gamma rays remaining without interacting $N_{\gamma}$ after traversing a distance $x$ through material with a density $\rho$ and mass-attenuation coefficient $\mu$ is

$$
N_{\gamma}(x)=N_{0} e^{-\mu \rho x}
$$


This exponential decrease in $N_{\gamma}(x)$ is observed in the experimental data in Figure 8 and in the Monte Carlo calculation in Figure 11. The number of gamma rays interacting at any depth is proportional to the number left

$$
\frac{d N_{\gamma}}{d x}=-\mu \rho N_{\gamma}
$$

Of these interactions, a fraction $k$, are small-angle Compton scatters. As the scattering angle approaches zero, the energy loss of the gamma ray also approaches zero. The number of smallangle gamma rays $N_{s a(x)}$ is therefore increased by $k$ times the number interacting $\mu \rho N_{\gamma}$.

However, because these small-angle gamma rays have virtually the same energy as the original gamma rays, they interact at the same rate $\mu \rho$, proportional to the number $N_{s a}$ there are. The differential equation for number of small-angle gamma rays is

$$
\frac{d N_{s a}}{d x}=k \mu \rho N_{\gamma}-\mu \rho N_{s a}
$$

The solution to this differential equation is

$$
N_{s a(x)}=k N_{0} \mu \rho x e^{-\mu \rho x}
$$

This equation is shown in Figures 9 and 12 with experimental floor-tile data and the Monte Carlo data.

The ratio of the number of small-angle scattered gamma rays to the uninteracted gamma rays is

$$
\frac{N_{s a}(x)}{N_{\gamma}(x)}=k \mu \rho x
$$

This surprising result is shown in Figure 10 for the experimental floor-tile data and Figure 13 for the Monte Carlo data. 


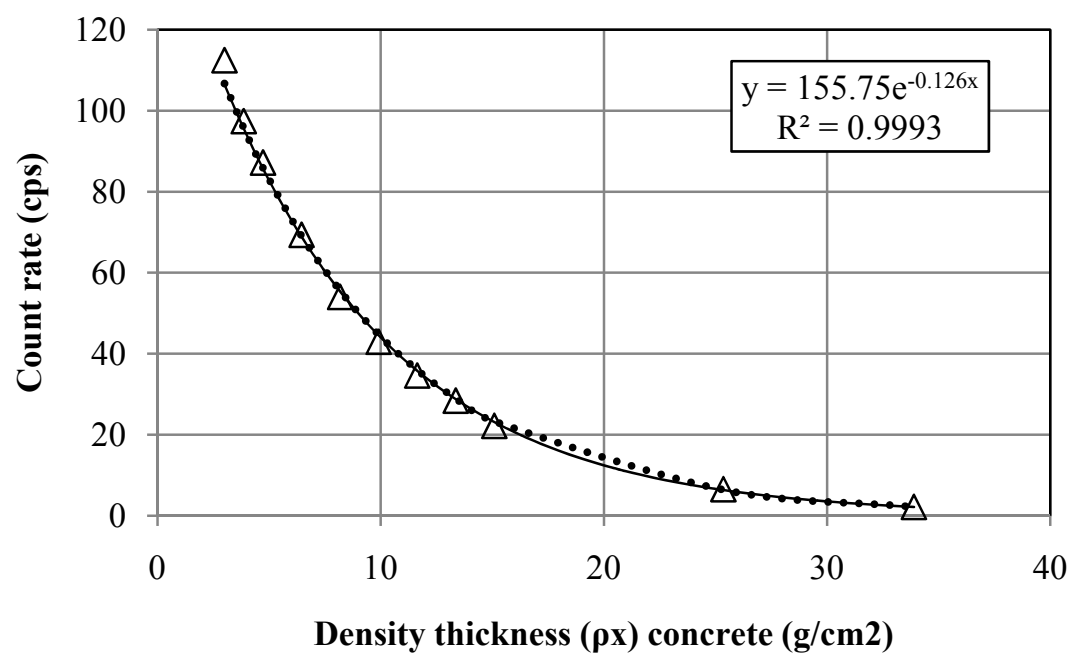

Figure 8: Count rates from the floor tile experiment. The source was set at various depths from Position 0 to Position 17 as shown in Figure 2. The depth is shown in units of density thickness $\boldsymbol{\rho x}\left(\boldsymbol{g} / \mathbf{c m}^{2}\right)$.

Position 0 was set to $3 \mathbf{g} / \mathbf{c m}^{2}$ to represent the detector housing. The Dotted line comes from Equation (1) with the following parameters: $N_{0}=155.75 \mathrm{cps}, \mu=0.126 \mathrm{~cm}^{2} / \mathrm{g}$.

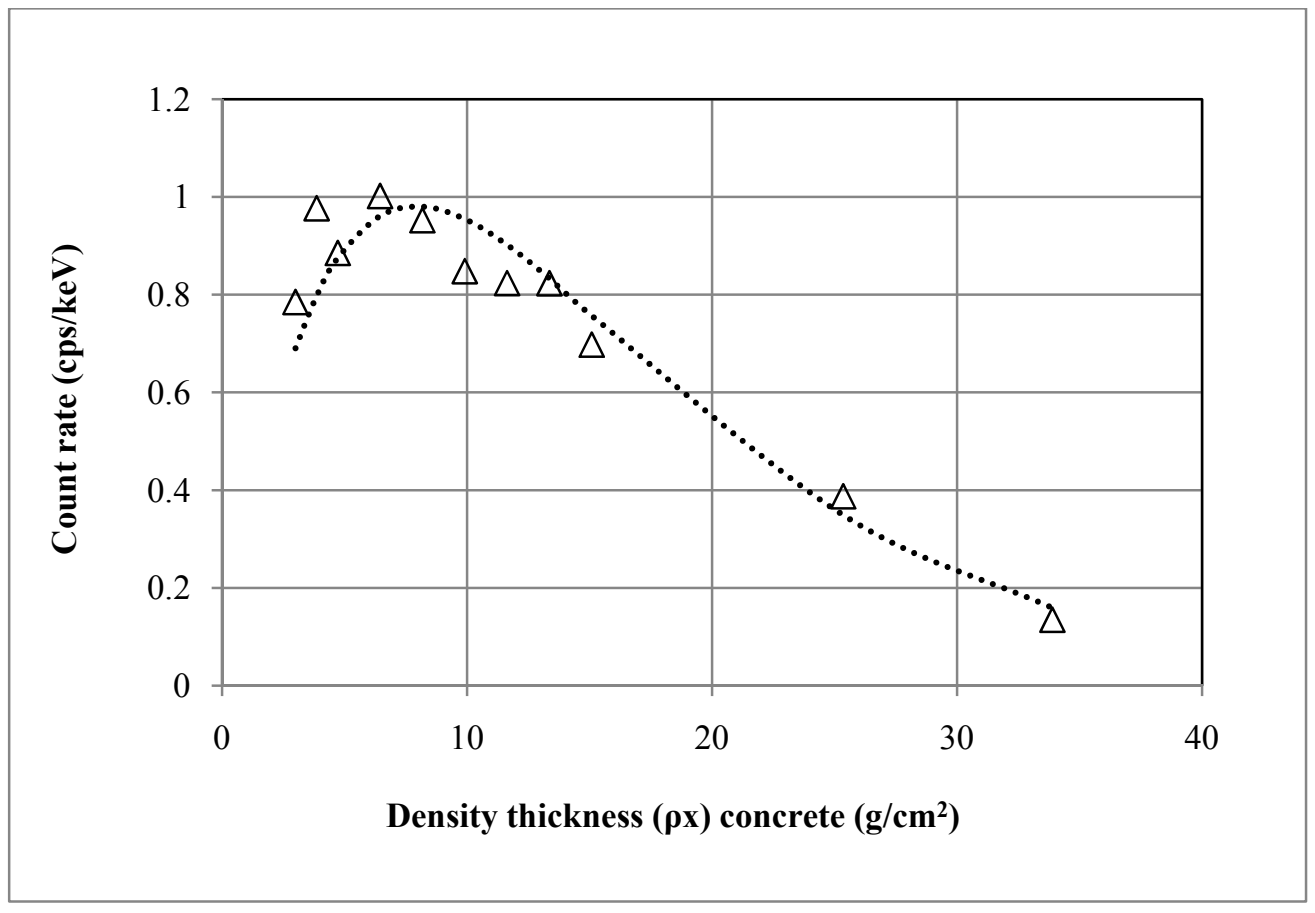

Figure 9: The small-angle scattering discontinuity in units of $(\mathrm{cps} / \mathrm{keV})$ from the experimental floor-tile data. The dotted line is from Equation (2) with the following parameters: $\boldsymbol{N}_{\mathbf{0}}, \boldsymbol{\mu}, \boldsymbol{\rho x}$, as in Figure 8. $\boldsymbol{k}=\mathbf{0 . 0 1 7 1}$ from the theoretical evaluation. The ROI was $1.07 \mathrm{keV}$ wide. A larger ROI of $4.62 \mathrm{keV}$ was also used. It produces a smoother curve but is biased high because of a small peak below the $185.71 \mathrm{keV}$ peak. 


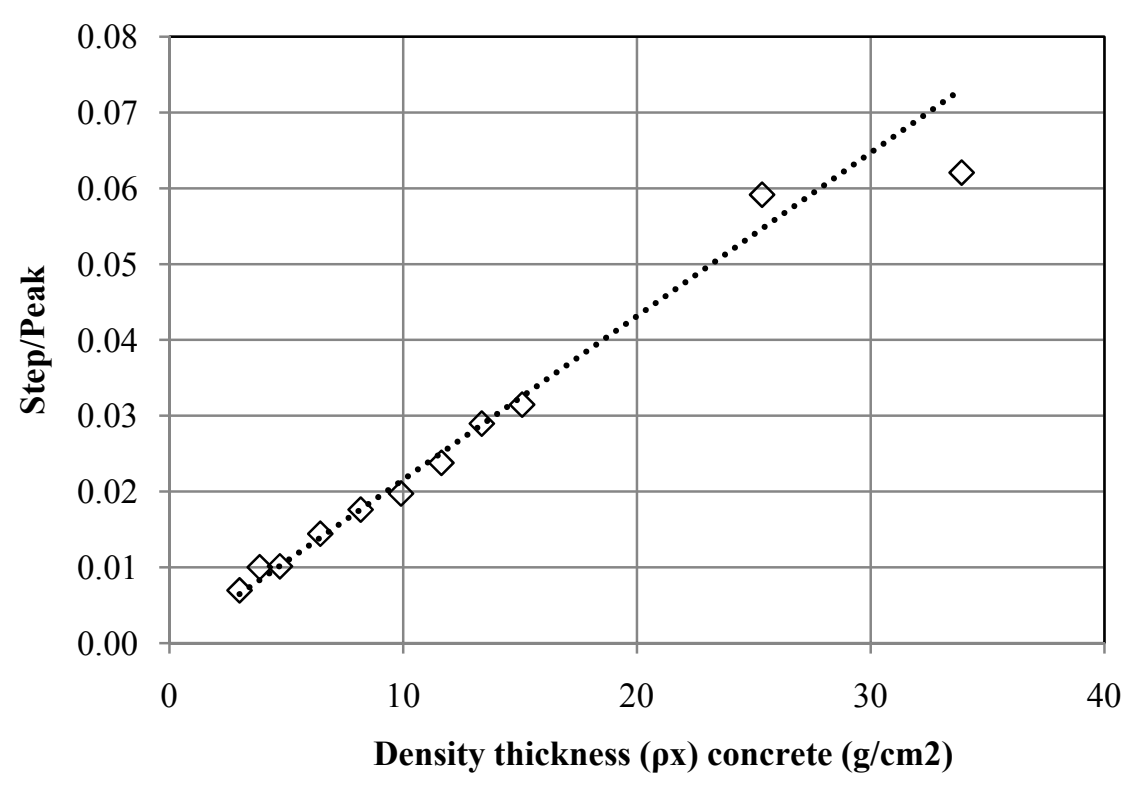

Figure 10: The ratio of the count rate in the peak to the discontinuity along with the theoretical equation $\frac{N_{s a(x)}}{N_{\gamma}(x)}=\boldsymbol{k} \boldsymbol{\mu} \boldsymbol{\rho} \boldsymbol{x}$ with the parameter values from Figures 8 and 9 and Table 4.

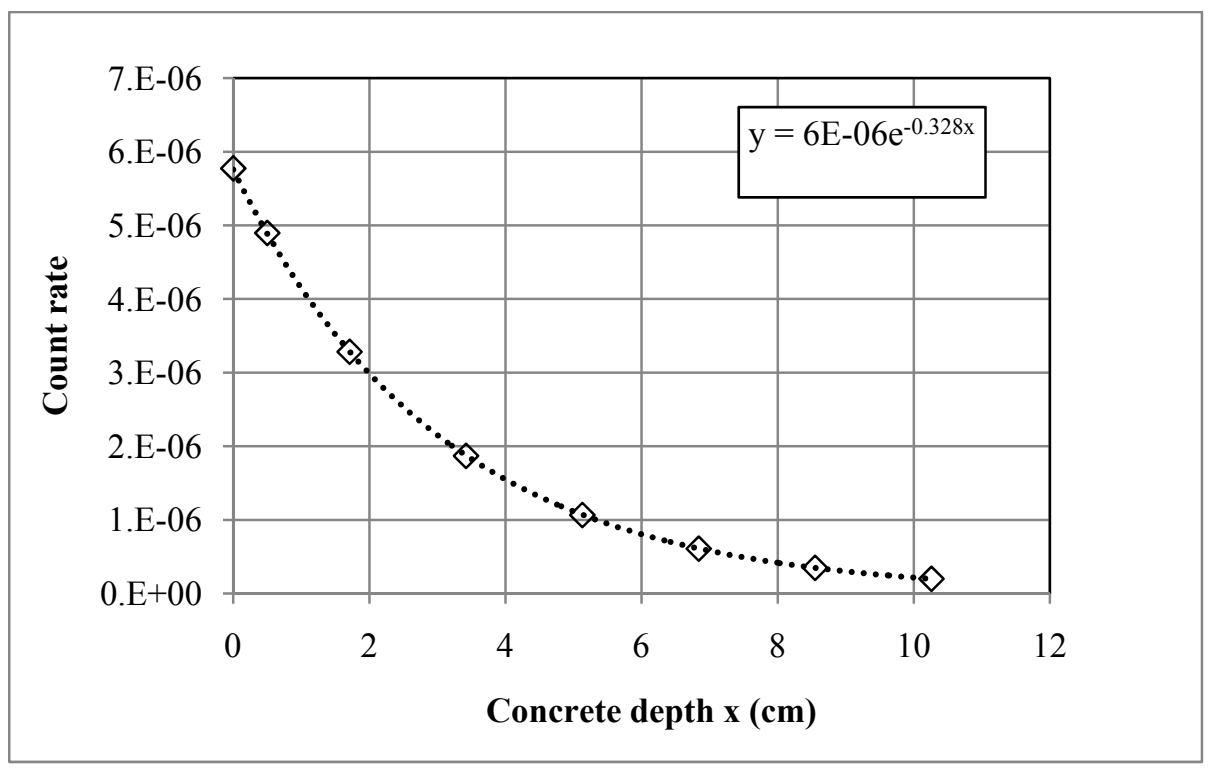

Figure 11: Count rates from the Monte Carlo calculation. The source was set at discrete depths in concrete. The count rate is per single gamma ray emitted. The Dotted line comes from Equation (1) with the following parameters: $N_{0}=6 \times 10^{-6}, \mu \rho=0.328 \mathrm{~cm}^{-1}$. The independent variable is in units of $(\mathrm{cm})$. A density of $2.3 \mathrm{~g} / \mathrm{cm}^{2}$ concrete was used in the model. 


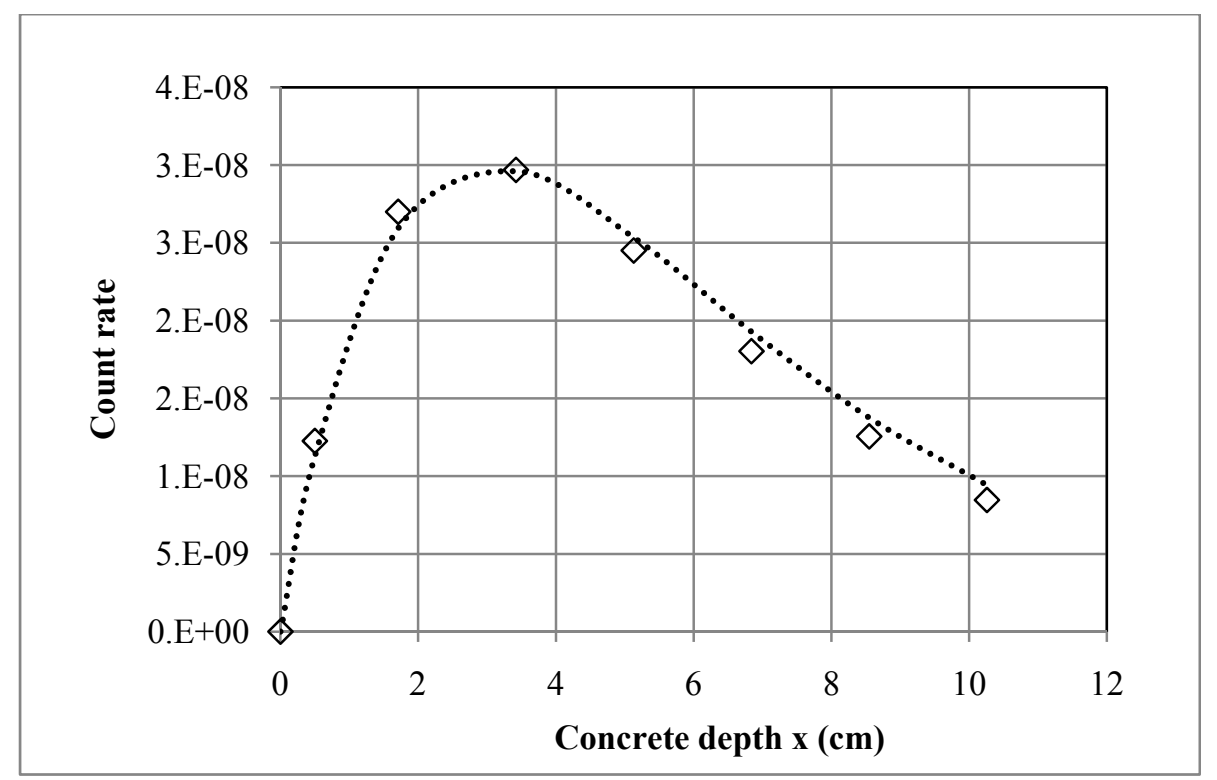

Figure 12: The small-angle scattering discontinuity from the Monte Carlo calculation in units of single count per gamma ray emitted per keV. The dotted line is from Equation (2) with the following parameters: $\boldsymbol{N}_{\mathbf{0}}, \boldsymbol{\mu} \boldsymbol{\rho}$, as in Figure 11. $k=0.0135$. The independent variable is in units of $(\mathrm{cm})$. The density of the concrete was $2.3 \mathrm{~g} / \mathrm{cm}^{3}$. The ROI was $2.5 \mathrm{keV}$ wide.

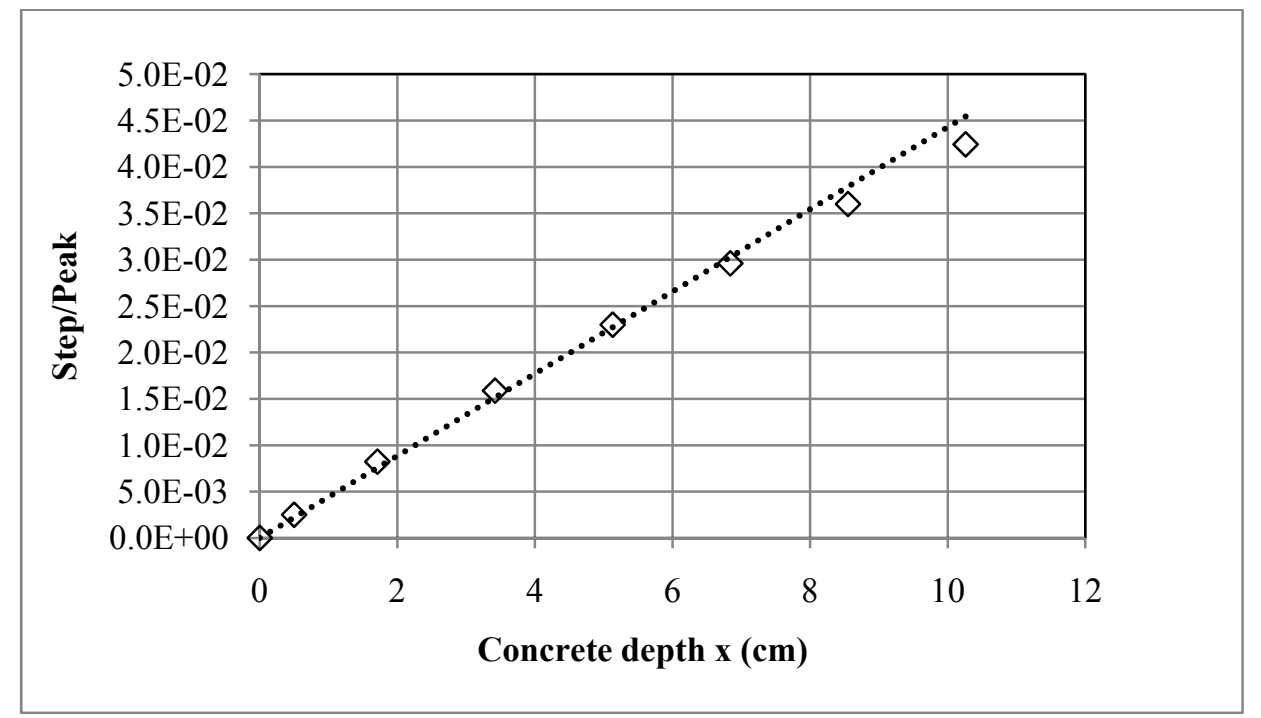

Figure 13: The ratio of the count rate in the peak to the discontinuity from the Monte Carlo calculation along with the theoretical equation $\frac{N_{s a(x)}}{N_{\gamma}(x)}=k \mu \rho x$.

The parameters used in the development of the theoretical calculation of the small-angle discontinuity are summarized in Table 4. The determination of the small-angle fraction $k$ will be developed in the following section using the Klein-Nishina equation. In practice the small-angle fraction $k$, the mass-attenuation coefficient $\mu$, and density $\rho$ are calculated from knowledge of the composition of the item under investigation. 
Table 4: Summary of parameters used for the theoretical development of small-angle scattering. The operational equations, Equations (3) and (7), only require the small-angle fraction k, the massattenuation coefficient $\mu$, and density $\rho$ are calculated from knowledge of the composition of the item under investigation

\begin{tabular}{|c|l|l|}
\hline Parameter & Experiment & Monte Carlo \\
\hline $\mathrm{N}_{0}$ & 155.8 & $6 \mathrm{E}-6$ \\
\hline$\mu$ & $0.126 \mathrm{~cm}^{2} / \mathrm{g}$ & $0.142 \mathrm{~cm}^{2} / \mathrm{g}$ \\
\hline$\rho$ & 1.36 to $2.07 \mathrm{~g} / \mathrm{cm}^{3}$ & $2.3 \mathrm{~g} / \mathrm{cm}^{3}$ \\
\hline $\mathrm{k}$ & $0.0171 / \mathrm{keV}$ & $0.0135 / \mathrm{keV}$ \\
\hline $\mathrm{dE}$ & $\begin{array}{l}4.62 \mathrm{keV} \text { and } \\
1.07 \mathrm{keV}\end{array}$ & $2.5 \mathrm{keV}$ \\
\hline
\end{tabular}

\section{Klein-Nishina equation:}

The constant $k$ in the ratio of small-angle scatters to peak in Equation (3) can be determined by the Klein-Nishina equation. This equation relates the differential cross-section by angle of scatter for Compton scattering. It is typically written as

$$
\frac{d \sigma}{d \Omega}=\frac{Z}{2} \alpha^{2} \mathrm{r}_{\mathrm{c}}^{2}\left(\frac{\mathrm{E}}{\mathrm{E}_{\gamma}}\right)^{2}\left[\left(\frac{\mathrm{E}}{\mathrm{E}_{\gamma}}\right)+\left(\frac{\mathrm{E}_{\gamma}}{\mathrm{E}}\right)-1+\cos ^{2}(\theta)\right]
$$

where $\Omega$ is the solid angle, $\mathrm{E}_{\gamma}$ is the original gamma-ray energy, $185.71 \mathrm{keV}$ in this case, $\mathrm{E}$ is the energy of the scattered gamma ray, $\theta$ is the angle of scatter from the original direction, $Z$ is the atomic-number of the element, and $\alpha^{2} r_{c}^{2}=0.0794$ barns is the square of the classical electron radius. The ratio of the scattered energy to the original energy comes from conservation of energy and momentum

$$
\left(\frac{E}{E_{\gamma}}\right)=\frac{1}{1+\frac{E_{\gamma}}{m_{e} c^{2}}(1-\cos (\theta))}
$$

where $m_{e} c^{2}=511 \mathrm{keV}$ is the rest-mass energy of an electron. Because the small-angle scatter results in a continuum from the peak energy $\mathrm{E}_{\gamma}$ downward, it must be normalized by energy. ${ }^{6}$ The count rate in the continuum depends on the width in energy of the region counted. Therefore the differential cross-section with respect to energy is needed. This differential cross section is determined by

where

$$
\frac{d \sigma}{d \mathrm{E}}=\frac{d \sigma}{d \Omega} \frac{d \Omega}{d \theta} \frac{d \theta}{d E}
$$

\footnotetext{
${ }^{6}$ An alternative is to integrate the differential cross-section over the energy of the ROI.
} 
and

$$
\frac{d \Omega}{d \theta}=2 \pi \sin (\theta)
$$

$$
\frac{d \theta}{d E}=-\frac{\left(\cos ^{2}(\theta)-2 \cos (\theta)+1\right) \mathrm{E}_{\gamma}^{2}+2 m_{e} c^{2}(1-\cos (\theta)) \mathrm{E}_{\gamma}+\left(m_{e} c^{2}\right)^{2}}{m_{e} c^{2} \mathrm{E}_{\gamma}^{2} \sin (\theta)}
$$

Multiplying the three factors results in

$$
\begin{aligned}
\frac{d \sigma}{d \mathrm{E}}=\pi \mathrm{Z}^{2} \mathrm{r}_{\mathrm{c}}^{2} & \left(\frac{\mathrm{E}}{\mathrm{E}_{\gamma}}\right)^{2}\left[\left(\frac{\mathrm{E}}{\mathrm{E}_{\gamma}}\right)+\left(\frac{\mathrm{E}_{\gamma}}{\mathrm{E}}\right)-1+\cos ^{2}(\theta)\right] \\
& \cdot\left[\frac{\left(\cos ^{2}(\theta)-2 \cos (\theta)+1\right) \mathrm{E}_{\gamma}^{2}+2 m_{e} c^{2}(1-\cos (\theta)) \mathrm{E}_{\gamma}+\left(m_{e} c^{2}\right)^{2}}{m_{e} c^{2} \mathrm{E}_{\gamma}^{2}}\right]
\end{aligned}
$$

The small-angle scattering continuum intersects the peak at a zero scattering angle $\theta$. Therefore the differential cross-section is evaluated at zero.

$$
\left.\frac{d \sigma}{d \mathrm{E}}\right|_{\theta=0}=2 \pi \mathrm{Z} \alpha^{2} \mathrm{r}_{\mathrm{c}}^{2}\left[\frac{m_{e} c^{2}}{\mathrm{E}_{\gamma}{ }^{2}}\right]=254.9(\mathrm{keV} \cdot \operatorname{barn})\left(\frac{\mathrm{Z}}{\mathrm{E}_{\gamma}{ }^{2}}\right)
$$

The differential cross-section for $\theta=0$ depends only on the atomic-number $Z$ of the material and the energy $\mathrm{E}_{\gamma}$ of the gamma ray. The fraction of interactions which are small-angle Compton scatters $k$, is given by

$$
k=\frac{\left.\frac{d \sigma}{d \mathrm{E}}\right|_{\theta=0}}{\sigma}
$$

where the total cross-section $\sigma$ is taken from $\mathrm{XCOM}^{7}$ data.

Equation (4) is the differential cross-section per atom. In the case of combinations of elements, the cross-section of each element must be combined according to the relative abundance of the atoms in much the same way the total cross sections are combined to get either the linear $\mu \rho$ or mass attenuation coefficient $\mu$. We can call the analogous combination of differential crosssections $d(\mu \rho) / d E$. The detailed calculation for the various elements in concrete is shown in

\footnotetext{
${ }^{7}$ Berger, M.J., Hubbell, J.H., Seltzer, S.M., Chang, J., Coursey, J.S., Sukumar, R., Zucker, D.S., and Olsen, K. (2010), XCOM: Photon Cross Section Database (version 1.5). [Online] Available: http://physics.nist.gov/xcom [Thursday, 10-Mar-2011 16:46:23 EST]. National Institute of Standards and Technology, Gaithersburg, MD.
} 
Table 5. The constant is then evaluated as $k=\frac{d(\mu \rho) / d E}{\mu}=\frac{5.15 E-03}{3.01 E-01}=0.01711 / \mathrm{keV}$ from the results of combining the individual elements in proportion of their number density. ${ }^{8}$

Table 5: Klein-Nishina calculation of the small-angle scattering constant $\mathrm{k}$ in concrete. $\mathrm{k}=5.15 \mathrm{E}-03 / 3.01 \mathrm{E}-01=0.01711 / \mathrm{keV}$. The total cross section $\sigma$ comes from XCOM data. $\frac{d \sigma}{d \mathrm{E}}$ is calculated from Equation (4). The composition comes from NIST STAR data. ${ }^{9}$

\begin{tabular}{|c|c|c|c|c|c|c|c|}
\hline Element & $\mathrm{Z}$ & $\begin{array}{l}\text { Mass } \\
\text { fraction }\end{array}$ & $\begin{array}{c}\text { Number } \\
\text { density } \\
n\end{array}$ & $\begin{array}{c}\text { Total cross } \\
\text { section } \\
\sigma\end{array}$ & $\begin{array}{c}\text { Total } \\
\text { attenuation } \\
\text { coefficient } \\
\mu \rho=n \sigma\end{array}$ & $\frac{d \sigma}{d \mathrm{E}}$ & $\frac{d(\mu \rho)}{d \mathrm{E}}=\mathrm{n} \frac{d \sigma}{d \mathrm{E}}$ \\
\hline & & & (atom/barn'cm) & (barn/atom) & $(1 / \mathrm{cm})$ & (barn/atom/keV) & $(1 / \mathrm{cm} / \mathrm{keV})$ \\
\hline $\mathrm{H}$ & 1 & 0.01 & 0.01374 & 0.416 & $5.72 \mathrm{E}-03$ & 0.007 & $1.02 \mathrm{E}-04$ \\
\hline $\mathrm{C}$ & 6 & 0.001 & 0.00012 & 2.511 & 2.90E-04 & 0.044 & $5.11 \mathrm{E}-06$ \\
\hline $\mathrm{O}$ & 8 & 0.529107 & 0.04581 & 3.368 & $1.54 \mathrm{E}-01$ & 0.059 & $2.71 \mathrm{E}-03$ \\
\hline $\mathrm{Na}$ & 11 & 0.016 & 0.00096 & 4.703 & $4.53 \mathrm{E}-03$ & 0.081 & $7.84 \mathrm{E}-05$ \\
\hline $\mathrm{Mg}$ & 12 & 0.002 & 0.00011 & 5.167 & 5.89E-04 & 0.089 & $1.01 \mathrm{E}-05$ \\
\hline $\mathrm{Al}$ & 13 & 0.033872 & 0.00174 & 5.642 & $9.81 \mathrm{E}-03$ & 0.096 & $1.67 \mathrm{E}-04$ \\
\hline $\mathrm{Si}$ & 14 & 0.337021 & 0.01662 & 6.133 & $1.02 \mathrm{E}-01$ & 0.103 & $1.72 \mathrm{E}-03$ \\
\hline $\mathrm{K}$ & 19 & 0.013 & 0.00046 & 8.921 & $4.11 \mathrm{E}-03$ & 0.140 & $6.47 \mathrm{E}-05$ \\
\hline $\mathrm{Ca}$ & 20 & 0.044 & 0.00152 & 9.568 & $1.45 \mathrm{E}-02$ & 0.148 & $2.25 \mathrm{E}-04$ \\
\hline $\mathrm{Fe}$ & 26 & 0.014 & 0.00035 & 14.450 & $5.02 \mathrm{E}-03$ & 0.192 & $6.67 \mathrm{E}-05$ \\
\hline Total & & 1.000 & & & $3.01 \mathrm{E}-01$ & & $5.15 \mathrm{E}-03$ \\
\hline
\end{tabular}

\section{Continuous distribution}

In a concrete floor contaminated by uranium solution, it is expected that the uranium source is distributed from the surface to some depth in the concrete. Although this concentration would probably decline with depth, a first approximation is that it is uniformly concentrated to some depth. The previous small-angle scattering theory can be generalized to the distributed case. Rather than a source $N_{0}$ at a discrete depth, we have a distributed source mixed with the concrete in a concentration $\mathrm{c}$. The units of this concentration would be gamma rays per $\mathrm{cm}$. Therefore the number of gamma rays both increases with the depth in the concrete but also decreases from attenuation.

$$
\frac{d N_{\gamma}}{d x}=\mathrm{c}-\mu \rho N_{\gamma}
$$

The solution of this differential equation is

\footnotetext{
${ }^{8}$ A density of $2.3 \mathrm{~g} / \mathrm{cm}^{3}$ was used to get the number density in Table 5 . However, it is not necessary to know or assume a density. When this is done, the attenuation coefficient $(1 / \mathrm{cm})$ will become a mass-attenuation coefficient with units $\left(\mathrm{cm}^{2} / \mathrm{g}\right)$.

${ }^{9}$ M.J. Berger, J.S. Coursey, M.A. Zucker and J. Chang, "Stopping-Power and Range Tables for Electrons, Protons, and Helium Ions." Material composition http://physics.nist.gov/cgi-bin/Star/compos.pl, Concrete http://physics.nist.gov/cgi-bin/Star/compos.pl?matno=144
} 


$$
N_{\gamma}(x)=\frac{\mathrm{c}}{\mu \rho}\left(1-e^{-\mu \rho x}\right)
$$

The small-angle scattered gamma rays are therefore fed by the distributed source but also decreased by attenuation.

$$
\frac{d N_{s a}}{d x}=k \mu \rho N_{\gamma}-\mu \rho N_{s a}
$$

The solution of this differential equation then becomes

$$
N_{s a(x)}=\frac{c k}{\mu \rho}\left[1-e^{-\mu \rho x}(1+\mu \rho \mathrm{x})\right]
$$

Again the ratio of small-angle scattered gamma rays to source gamma rays can be determined as

$$
\frac{N_{s a}(x)}{N_{\gamma}(x)}=\frac{k\left[1-e^{-\mu \rho x}(1+\mu \rho \mathrm{x})\right]}{\left(1-e^{-\mu \rho x}\right)}
$$

This curve is shown in Figure 14 superimposed on the numerically integrated floor tile experimental data from Figure 4. The numerical integration was performed on the small-angle count rate in a $4.62 \mathrm{keV}$ ROI. The evaluation of $k$ assumes that the small-angle scattering continuum was normalized by energy. Therefore Equation (7) had to include that energy range. Because a source was placed above the concrete, and there is potential of small-angle scattering in the detector enclosure, a 0.04 offset in the ratio appears at the surface for the concrete at zero.

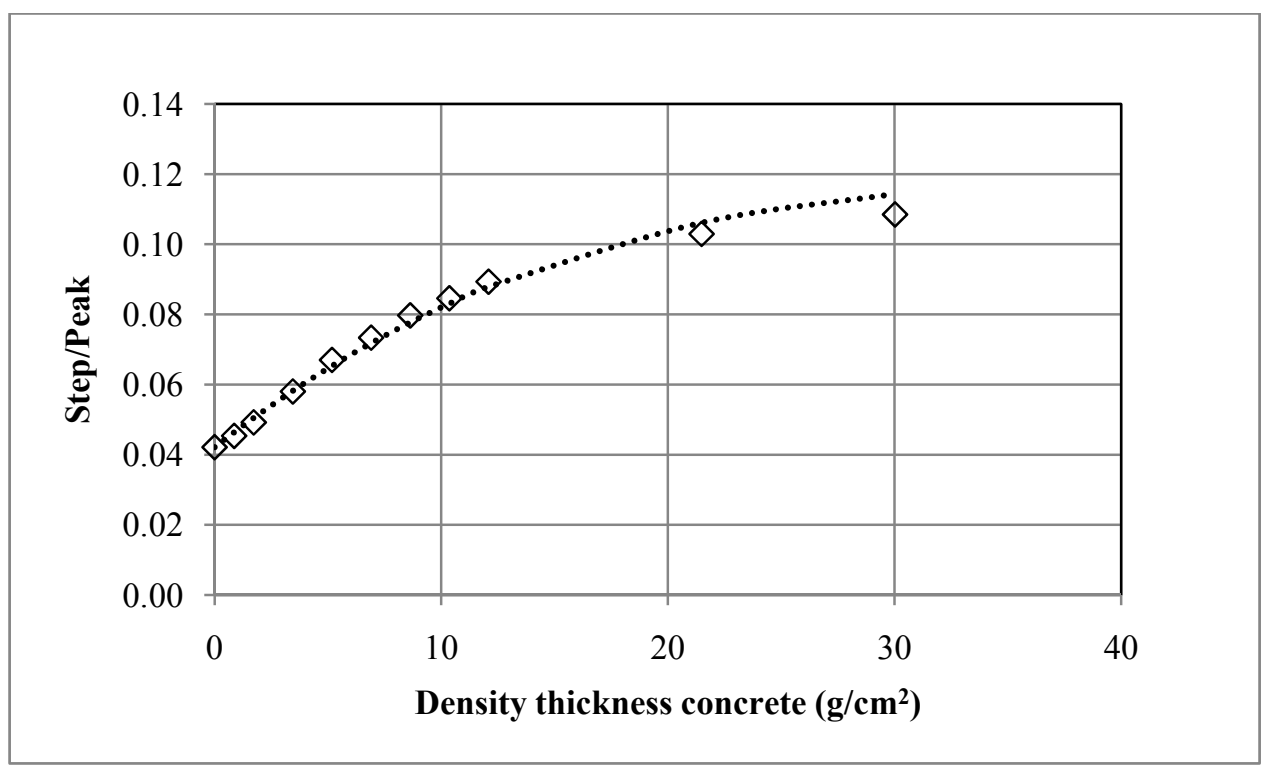

Figure 14: From the experimental data, the ratio of the small-angle discontinuity to the peak along with the theoretical Equation (7). The theoretical constant $k(0.01711 / \mathrm{keV})$ was multiplied by the ROI width of 
$4.62 \mathrm{keV}$ because the discontinuity was not normalized by the ROI width. A constant of 0.04 was added because position included a source before the surface of the concrete. Theoretically the count rate in both the discontinuity and the peak is zero at the surface when the depth is zero for a distributed source. The measured values are the numerical integral of the discontinuities from Figure 9 times $\Delta(\boldsymbol{\rho} \boldsymbol{x})$ of the tile.

A Monte-Carlo calculation was also performed for the continuous case. The geometry shown in Figure 6 was modified so that the gamma-ray source extended uniformly from the front surface to a depth $x$ in the concrete. The ratio of the small-angle scattering discontinuity to the peak divided the the energy delta of $2.5 \mathrm{keV}$ is shown in Figure 15 along with the Equation (7) theoretical result.

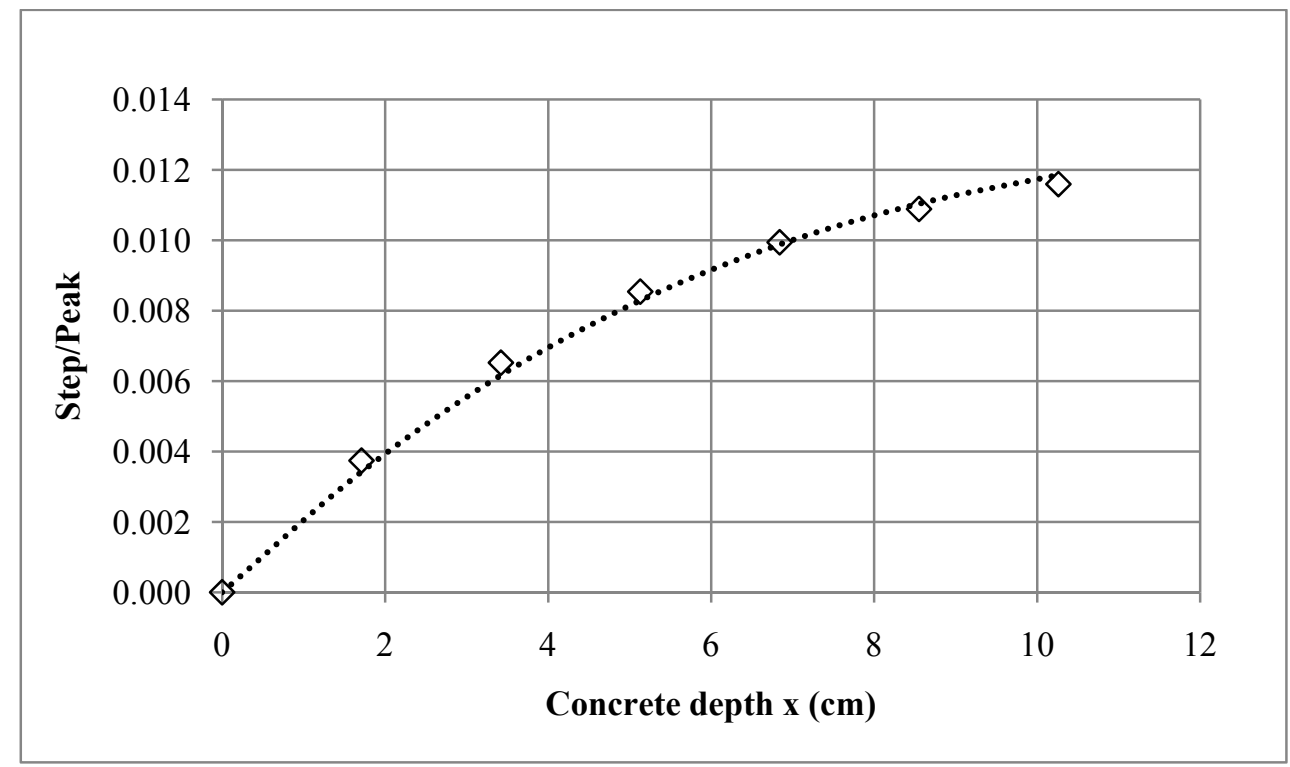

Figure 15: From the Monte Carlo calculation for the continuous distribution, the ratio of the count rate in the discontinuity to the peak along with the theoretical Equation (7). The theoretical constant $k(0.0135 / \mathrm{keV})$ was multiplied by the ROI width of $2.5 \mathrm{keV}$ because the discontinuity was not normalized by the ROI width. The count rate in both the discontinuity and the peak is zero at the surface when the depth is zero for a distributed source.

For a radioactive source at a discrete depth, the small-angle scattering continuum to peak ratio is linearly related to source depth. However, because both decline exponentially, at large depths, long count times will be required to determine the ratio accurately at large depths. In the continuous case, however, the incremental increase in the ratio decreases as depth increases. The practical depth that the method is useful for is not unlimited.

\section{Conclusion}

The small-angle scattering discontinuity divided by the gamma-ray peak can be used with the familiar variables of the attenuation calculation from Equation (3) for a container or Equation (7) for a matrix to estimate the depth of a gamma-ray source in a material. The additional constant $k$ is a function of the gamma-ray energy and the $\mathrm{Z}$ of the matrix or container material similar to the 
mass-attenuation coefficient. In fact it is merely the fraction of the mass-attenuation coefficient attributed to small-angle scattering per energy.

The operational equations are summarized here. The only variables are atomic-number $\mathrm{Z}$, gamma-ray energy $\mathrm{E}_{\gamma}$, mass-attenuation coefficient $\mu$, density $\rho$, and depth $x$ of a gamma-ray source. When the small-angle discontinuity is measured, density-thickness $\rho x$ can be calculated from these equations either directly from Equation (3) or by interpolation by Equation (7). It can be used in conjunction with differential attenuation.

The small-angle scattering differential cross-section is determined by Equation (4) from the atomic-number $\mathrm{Z}$ and gamma-ray energy $\mathrm{E}_{\gamma}$ according to

$$
\left.\frac{d \sigma}{d \mathrm{E}}\right|_{\theta=0}=254.9(\mathrm{keV} \cdot \operatorname{barn})\left(\frac{\mathrm{Z}}{\mathrm{E}_{\gamma}^{2}}\right)
$$

Dividing this differential cross-section by the total cross-section $\sigma$ gives the fraction $k$ of interactions which are small-angle Compton scatters from Equation (5)

$$
k=\frac{\left.\frac{d \sigma}{d \mathrm{E}}\right|_{\theta=0}}{\sigma}
$$

Multiplying this fraction $k$ by the mass-attenuation coefficient $\mu$, density $\rho$, and depth $x$ of a discrete gamma-ray source gives the magnitude of small-angle scattering discontinuity divided by the peak height from Equation (3)

$$
\frac{N_{s a}(x)}{N_{\gamma}(x)}=k \mu \rho x
$$

A continuous, uniform distribution in a matrix to a depth $x$ is given from the same variables $(\mu$, $\rho, x)$ from Equation (7)

$$
\frac{N_{s a}(x)}{N_{\gamma}(x)}=\frac{k\left[1-e^{-\mu \rho x}(1+\mu \rho \mathrm{x})\right]}{\left(1-e^{-\mu \rho x}\right)}
$$

The small-angle discontinuity can be used to determine the amount of intervening matter between a gamma-ray source and detector. It can be used in addition to differential attenuation, or when differential attenuation cannot be used such as a single gamma ray source such as Cs137. This depth is useful in estimating the attenuation of the gamma rays or to determine the structure of a nuclear device in a forensic situation. 